December 3, p. IOO) seeks to justify his action on the ground that " in a matter of such great importance . . . it is probably fair to conclude that, with the great majority of physicists, "silence gave consent.", This doctrine of silence is surely untenable. If an authority on acoustics pronounces views even on the fundamentals of sound, is an electrician to be held consenting when he forms no opinion or reserves it to himself? In the present case it should be added that whilst questions in geo-physics or astro-physics are often most interesting to the public, they hardly as yet touch the fundamentals of physics, but constitute merely theoretical applications. If we put at 5 per cent. the proportion of physicists who have studied for themselves any given problem in geo-physics, and who have the necessary qualifications to justify the expression of an opinion, re should probably indulge in an over-estimate. It is in fact only a very small minority of whom anything but silence could possibly have been expected.

In the next place, even if the doctrine of silence were accepted, the occasion for applying it does not exist. A considerable number of persons-some in my opinion imperfectly equipped for the task-have criticised the theories of Lord Kelvin and Prof. Tait. In his letter Prof. Poulton represents all such critics as geologists or zoologists, but in his B.A. address (NATURE, September 24, p. 502) he admitted the existence of mathematcal critics. Most of these critics had, I think, in reality as much claim to the title physicist as to that of mathematician. I myself five years ago, in two papers whose physical character was indicated by the title "Some Applications of Physics and Mathematics to Geology," while pointing out that in my opinion the critics were mistaken in supposing they had demonstrated the essential erroneousness of Lord Kelvin's work, advocated strongly the maintenance of an agnostic attitude towards the question of the solidity of the earth's interior. These papers appeared in the Philosophical Magazine, were reprinted in the "Annual Report of the Smithsonian Institution," and have been referred to since in several standard works. So far as I know, no attempt to controvert their arguments has been published, so that on the doctrine of silence they would seem to represent the views of the "majority of physicists." It is obvious to any mathematical physicist, and I should have hoped to others, that so long as the solidity of the earth's interior is an open question, no theoretical application of the mathematical equations for solids-whether to temperature or any other internal property - can be regarded as final.

My reason for advising Prof. Poulton to allow for possible errors in speculations other than Lord Kelvin's, and for commenting on the absence of any reference on his part to Lord Kelvin's recent experiments on rock conductivity, was as follows :-

The key-stone in Prof. Perry's valuable contribution to the subject, on which Prof. Poulton so largely relies, is the demonstration that, even on the assumption of a solid earth, the hypothesis of thermal homogeneousness does not necessarily supply an absolute maximum to the habitable age of the earth, inasmuch as higher estimates can be obtained on the simple hypothesis that the internal strata conduct better than the surface strata. This disposes of the necessary character of Lord Kelvin's conclusions on this subject-even if solidity be granted -but still may leave his estimate a not improbable one, so far as physical grounds are concerned, unless a presumption can be raised that the conditions of Prof. Perry's problem exist in nature. A study of Prof. Poulton's address led me to think that in his anxiety to increase the $a$ priori probability of the conditions postulated in Prof. Perry's solution, he was attaching undue weight to theoretical speculations which seemed to tell in its favour, while omitting all mention of recent direct experiments by Lord Kelvin which told against it. In my letter I quoted Prof. Poulton's own words, so far as space allowed, and certainly did not represent him as holding the theoretical evidence to be "conclusive."

The second half of my first letter was intended to show Prof. Poulton, by reference to his own address, another aspect of the case, viz. the serious inroads which would be made on a physicist's time if he criticised everything he thought erroneous. It seems that Prof. Poulton agrees mainly with my criticisms, only he maintains that the views criticised are products solely of my imagination. Flattering as it would be to my amour propre to believe my imagination so gifted, I must acknowledge the suspicion that most physicists who read Prof. Poulton's address, as published in NA'TURE, will find a simpler explanation. Take for instance Prof. Poulton's remark, "the earth, even when solid, will alter its form when exposed for a long time to the action of great forces," and my criticism, "here and in the rest of the passage is a strong flavour of the erroneous view that a solid is rigid in the mathematical sense, except when viscous under great and prolonged stress." Elasticians, I suspect, will fail to recognise this as the criticism solely of an exuberant imagination.

One word more: Prof. Poulton speaks as if the opinion of "the majority of physicists" were binding on their fellows. Now in the first place the voice of the majority is not yet recognised as dominant in science, and in the second place no provision exists for collecting suffrages. In the society of zoologists and geologists the individual physicist may possibly become a very fountain of universal knowledge, but amongst his peers he is chary about expressing too definite an opinion on questions he has not specially studied. CHARLES CHREE.

December 7 .

\section{The Satellite of Procyon.}

THE announcement in the Astronomical Column of NATURE for November I9 (p. 62), of the discovery of a close companion io Procyon by Prof. Schaeberle, with the 36-inch telescope of the Lick Observatory, will be extremely interesting to those who know anything of the history of the investigations which have been made as to the cause of the irregularity in the proper motion. of Procyon observed by Bessel in 1844, and Mädler in 1851. Following up their observations, Dr. Auwers in I86I computed an orbit on the assumption of a circular motion in a plane perpendicular to the line of sight, round a point about $\mathbf{I}^{\prime \prime} \cdot 2$ distant, having a period of about 40 years, the position angle being about $90^{\circ}$ for 1873 , and this, with an assumed motion of about $9^{\circ}$ per annum, would make the present angle about $300^{\circ}$ for the hypothetical companion.

Otto Struve measured a supposed new companion in 1873, March 28, with the 15 -inch refractor at Pulkowa, and found, as a mean of several measures, the P. angle $90^{\circ} \cdot 24$, and distance $\mathrm{I2}^{\prime \prime} \cdot 49$; and also in 1874 , April Io, when he measured the P. angle $99^{\circ} \cdot 6$, and distance $I^{\prime \prime} \cdot 67$; but, singular to relate, though looked for with the 26 -inch telescope at Washington on several occasions from November I873 until January 1876 , and also by the three Clarks (father and two sons) with the McCormick $26 \frac{1}{4}$-inch telescope, Otto Struve's companion was missed by both instruments.

The Washington observers, however, gave estimated places for three new companions within $10^{\prime \prime}$ distance; but when $\mathrm{Mr}$. S. W. Burnham, at the Lick Observatory, examined Procyon on the early morning of November I8, I888, with a view to confirm all these observations or otherwise, he gave the following record :- " Procyon. - Carefully examined with all powers up to 3300 on the 36 -inch under favourable conditions. Large star single, and no near companion."

Should the existence of the new companion, now said to be discovered by Prof. Schaeberle, be confirmed by other large instruments elsewhere, the orbit will likely prove to be an excentric one, and that the companion has just emerged from the dazzling rays of the bright primary sufficient to allow it to be measured with the 36 -inch ; but after the previous experiences in the supposed discovery of other companions, astronomers will be the more inclined to await further observations, especially as the new Yerkes $41^{3}$-inch object-glass is now ready for mounting at the newly-erected Observatory, and will be in the hands of such keen-ryed and experienced double-star observers as Messrs. Burnham and Barnard.

In NATuRE for March 28, r889 (p. 510), Mr. J. M. Barr, of St. Catharine's, Ontario, suggested that photography might be employed to obtain the image of a satellite on the sensitive plate by intercepting the image of the brilliant primary by a suitable screen, and in NATURE for April in following (p. 558), in addition to other particulars, I referred to the instrumental difficulties connected with getting the impress of a probably faint companion, at the extremely close distance of two to three seconds of arc.

ISAAC W. WARD

Belfast, November 30 .

The Leonid Meteor Shower.

If the recent observations proved that comparatively few meteors of this system were visible, they were interesting as showing the maximum to have occurred on the morning of

NO. I 4I6, vOL. 55] 